\title{
Cytokine Level and Symptoms of Schizophrenia
}

\author{
Mustafa M. Amin ${ }^{1 *}$ (i), Elmeida Effendy (D) \\ Department of Psychiatry, Faculty of Medicine, Universitas Sumatera Utara, Medan, Indonesia
}

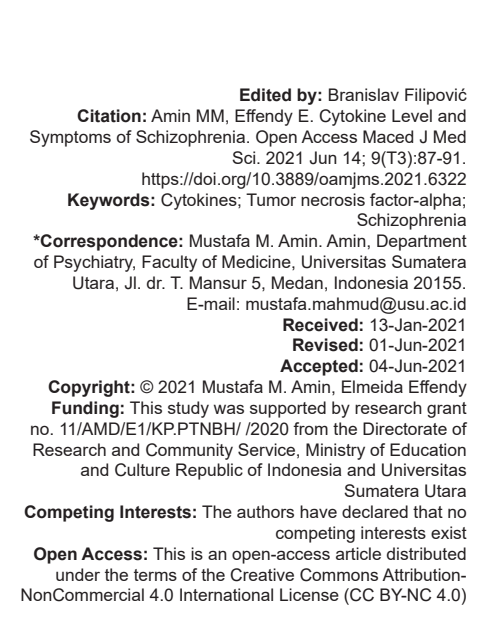

\section{Introduction}

Schizophrenia is a psychotic disorder that has the characteristics of delusions, hallucinations, disorderly behavior, disturbances in thinking, and other negative symptoms. This disease has prevalence in the United States around $0.3-0.7 \%$, yet this figure varies by country, race/ethnicity, or geographical condition of an area. The incidence is higher in men compared to women, especially to negative symptoms and worse disease outcomes [1]. During this time, it is estimated that inflammation and immune system dysfunction have a close relationship with schizophrenia. The inflammatory process and cytokines may have pathogenic importance for the development of schizophrenia both in the process of brain development and in the acute condition of the disease. Cytokines mediate infection, hypoxia, and ischemia in fetal brain development and the relationship between prenatal exposure to infection and the risk of schizophrenia is not limited to one infectious agent. The increased risk of developing schizophrenia is thought to be due to the role of modulation from cytokines. Cytokines are low molecular weight proteins that mediate immune and inflammatory responses and are excreted by glial and neuronal cells in the central nervous system and regulate brain development. Proinflammatory cytokines include, such as interleukin-1 $\beta$ (IL-1 $\beta$ ), IL-6, and tumor necrosis factor (TNF)-alpha. The consequences of prolonged inflammation are often unfavorable, and in the condition of schizophrenia, it will result in chronic and decrease neuropsychiatric conditions over time [2].

One of the cytokines that have an essential role for schizophrenia is TNF-alpha, TNF-alpha level was found to be significantly increased in people with schizophrenia (PwS) compared to healthy people in the control group [3], [4], [5], [6]. Other studies with the same results were also reported by O'Brien et al. [7], who found significant differences in TNF-alpha level in the PwS group of $13.49 \mathrm{pg} / \mathrm{ml} \pm 0.42$ and $6.79 \mathrm{pg} / \mathrm{ml}$ \pm 0.42 in the control group. However, different results which found lower TNF-alpha level in the PwS group was also reported by Tian et al. [8], Lv et al. [9], and Zhu et al. [10].

Previous studies showed inconsistent results regarding the TNF-alpha level in PwS, some of them reported an increase and others reported a decrease in TNF-alpha level. To the best of the authors' knowledge regarding the current studies that discuss this issue, there have been no studies that assessed TNF-alpha level on PwS with a specific race, and it encouraged the authors to do this study measured the MalayanMongoloid Race in Medan, Indonesia. The results were expected to provide an overview of TNF-alpha level in PwS of Malayan-Mongoloid race and its correlation with positive and negative symptoms in schizophrenia. 


\section{Methods}

This study was a cross-sectional analytic study, which compared two groups, namely the PwS group and the control group. Subjects were collected for 3 months at the Mental Hospital of Provinsi Sumatra Utara, which was a referral hospital for people with a mental health condition in the province. Inclusion criteria for PwS were: Malayan-Mongoloid race, schizophrenic patients, diagnosed according to the $10^{\text {th }}$ edition of the International Classification of Disease and Related Health Problems criteria, aged $15-40$ years, cooperative and willing to be interviewed. The exclusion criteria were: Having a history of previous mental disorders and a general medical condition that affects brain structure, obesity. Meanwhile, the inclusion criteria of the control group were: Malayan-Mongoloid race, age 15-40 years, cooperative and willing to be interviewed, and did not have a family history of mental disorders. Exclusion criteria for the control group were: Having a history of previous mental disorders and a general medical condition that affected brain structure, obesity.

The sample size calculation used the following formula: In this study, the sample size was $51 \mathrm{PwS}$ and 52 controls. The research sample was obtained using nonprobability sampling with a consecutive sampling type. Furthermore, the explanation was given to the subjects and their family relations, while in the control group, the explanation was given directly to the subjects, and directly signed the consent letter after they already understood the purpose of this study. Before the blood was drawn, the subjects were asked to fast for 8-10 h. Blood plasma sampling was carried out as follows: the subject would undergo a blood test, which was taken with a sterile syringe from a $6 \mathrm{ml}$ median cubital vein at 7-9 a.m. The blood was put into a vacutainer containing ethylenediaminetetraacetic acid and stored at $4-8^{\circ} \mathrm{C}$ until plasma was obtained. The ELISA examination was then performed using the Quantikine Human TNF-alpha kit from R\&D system and read the results using the ThermoFisher machine.

\section{Results and Discussions}

The results of this study were divided into three subsections, namely baseline comparison between groups, comparison of TNF-Alpha level between PwS and control groups, and TNF-Alpha level in PwS with the Malayan-Mongoloid Race.

\section{Baseline comparison between groups}

Based on Table 1, it was found that most of the subjects of the PwS group were men, they were $39(76.5 \%)$, with an average age of $36(28.00-40.00)$
Table 1: Baseline comparison between groups

\begin{tabular}{lll}
\hline Variables & Group & \\
\cline { 2 - 3 } & Schizophrenia $(\mathrm{n}=51)$ & Control $(\mathrm{n}=52)$ \\
\hline Sex & $39(76.5 \%)$ & $28(53.8 \%)$ \\
Male & $12(23.5 \%)$ & $24(46.2 \%)$ \\
Female & $36.00(28.00-40.00)$ & $29.00(18.00-40.00)$ \\
Age & $96.00(81.00-110.00)$ & \\
PANSS Score &
\end{tabular}

years, and a positive and negative syndrome scale score of 96.00 (81.00-110.00). The results of this study found that there were more PwS subjects with male sex, 39 of the total $51 \mathrm{PwS}$ subjects $(76.5 \%)$ it was the same as those reported by Lv et al. [9] 72 people $(80.89 \%, \mathrm{n}=89)$, Tian et al. [8] and Naudin et al. [3]. Li et al. [11] concluded why the male of PwS was hospitalized more than female of PwS, and it was because female of PwS was $<50 \%$ experienced inpatient care and more responsive to treatment. Some other possibilities that cause the number of PwS male more often hospitalized compared to PwS female were because the male of PwS was less adherent to treatment, the ratio of the number of PwS male more than PwS female, and often commit suicide so that more often hospitalized [12].

\section{Correlation of TNF-alpha level with PANSS scores in the schizophrenia group}

Table 2 showed that in the schizophrenia group, statistically, there was no significant correlation between TNF-alpha level and PANSS score $(p=0.594)$, the correlation was very weak, but it had a positive correlation means that the higher TNF-alpha level was, the higher PANSS score would be. Ergün et al. also reported the lack of correlation between TNF-alpha and PANSS score, [13], with a negative correlation direction. Kubistova et al. [14], Ajami et al. [15], and Luo et al. [16] reported similar results, who found that there was no TNF-alpha correlation with PANSS score on PwS. However, a different result from those studies was reported by Turhan et al. [17], who found the level of TNF-alpha serum had significant correlation, weak correlation, and negative correlation directions.

Table 2: Correlation test result between the tumor necrosis factor-alpha level and the PANSS score in the schizophrenia group

\begin{tabular}{llll}
\hline Group & \multicolumn{2}{l}{ PANSS score } & $\mathrm{p}$-value \\
\cline { 2 - 4 } & $\mathrm{n}$ & $\mathrm{r}$ & 0,594 \\
\hline Schizophrenia & 51 & 0,076 & 0,594 \\
\hline Tumor necrosis factor-alpha level & & &
\end{tabular}

Thus far, it is still unclear how cytokines can affect clinical symptoms in PwS [16]. One theory states that TNF-alpha, which is one of the proinflammatory cytokines, also experiences an increase in Th1 and Th17 activation, which in turn activates the hypothalamic-pituitary-adrenal axis and subsequently activates the secretion of serotonin neurotransmitters or releases neurotoxic glutamic acid [15]. The positive correlation between TNF-alpha and PANSS score in this study could indicate that if there is an increase in TNF-alpha, there has been an acceleration of the neuro 
progressive process, which could eventually worsen the symptoms of PwS [17]. We have provided Figure 1 to show the scatter graph of the correlation analysis.

\section{Comparison of TNF-alpha level between the schizophrenia and control groups of the Malayan-Mongoloid race}

Mann-Whitney test result in Table 3 shows that the variable of TNF-alpha level showed a value of $p<0.001$, which means that there was a significant difference in TNF-alpha level between the schizophrenia group and the control group.

Table 3: Results of comparative analysis of tumor necrosis factor-alpha level between the schizophrenia and the control group

\begin{tabular}{llll}
\hline Variable & Group & & \\
\cline { 2 - 4 } & Schizophrenia $(n=51)$ & Control $(n=52)$ & $p$ value \\
\hline TNF-alpha level ${ }^{\mathrm{a}}$ & $3.17(0.60-43.80)$ & $16.40(5.18-56.10)$ & $<0.001$ \\
\hline${ }^{\mathrm{a}}$ Mann-Whitney test. & & &
\end{tabular}

In this study, the mean of TNF-alpha levels in the PwS group was lower at 3.17 (0.60-43.80) $\mathrm{pg} / \mathrm{dl}$, compared to the control group at 16.40 (5.18$56.10) \mathrm{pg} / \mathrm{dl}$. There were several similar results of the studies which found the lower TNF-alpha level in the PwS group compared to the control group, they were the studies conducted by Tian et al. [8], who reported TNFalpha level in the PwS group $(9.5 \pm 2.1 \mathrm{pg} / \mathrm{dl})$ compared to the control group $(10.7 \pm 1.8 \mathrm{pg} / \mathrm{dl})$. Then, Lv et al. [9] found TNF-alpha level in the PwS group (10.1 $\pm 2.0 \mathrm{pg} /$ dl) and control group $(37.8 \pm 3.4 \mathrm{pg} / \mathrm{dl})$, and Zhu et al. [10] who obtained the TNF-alpha value in the PwS group $(8.2 \pm 2.0 \mathrm{pg} / \mathrm{dl})$ and the control group $(28.1 \pm 13.3 \mathrm{pg} / \mathrm{dl})$. Meanwhile, the other studies show different results that TNF-alpha levels were higher in the PwS group compared to the control group reported by Naudin et al. [3] and Simamora et al. [18]. Some conditions that are thought to affect lower TNF-alpha levels are the chronicity of schizophrenia and antipsychotic drugs consumed by PwS [9]. Low levels of inflammatory cytokines in the brain can still affect complex brain functions such as nerve activity, memory, mood, anxiety, and cognition [19], [20]. Cytokines are thought to be involved in regulating the work of several neurotransmitters such as dopamine, serotonin, noradrenaline, and glutamate [21]. All of these neurotransmitters have more or less influence in the etiology of schizophrenia, specifically dopamine. In this case, TNF-alpha plays an important role in regulating multiple events, including immunity and inflammation. It can be concluded that the decrease in TNF-alpha level in the PwS group indicates that there has been a defect during the induction of inflammatory pathways or active inhibition of the cytokines [9].

This research is the first study in Indonesia which was specializing on PwS of Malayan-Mongoloid Race, and there were no previous studies which focused on PwS in certain races. Reports from Ferguson

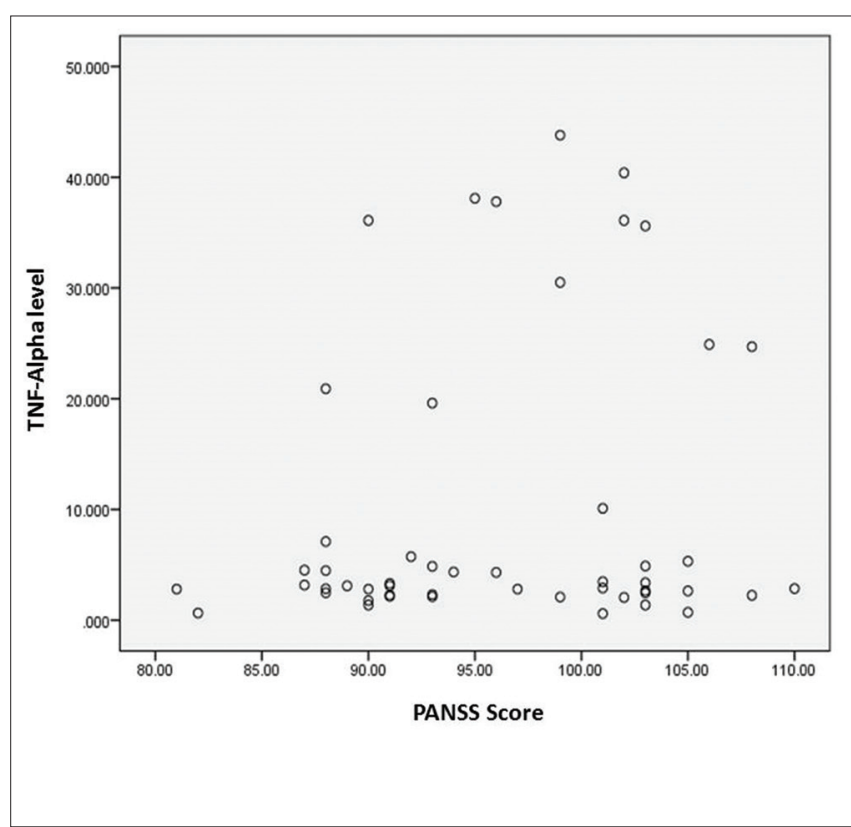

Figure 1: Scatter graph correlation analysis results between the tumor necrosis factor-alpha level and PANSS score

et al. [22], African-American Race can have higher cytokine levels compared to the Caucasian Race. Other studies also find the tendency of African-American Race to have higher cytokine level [23], [24]. The same tendency as the African-American Race was also found in the Asian Race [25]. Meanwhile, a study conducted by Liu et al. [26] found that Han race in China tended to have certain diseases if they had a TNF-alpha polymorphism and one study that found cytokine level could be more elevated in Caucasoid Race compared to African-American Race for the response of certain vaccines [27]. In this case, it can be concluded that race is also one of the factors toward differences in cytokine levels of each person. Figure 2 is provided to show the boxplot graph of Mann-Whitney test.

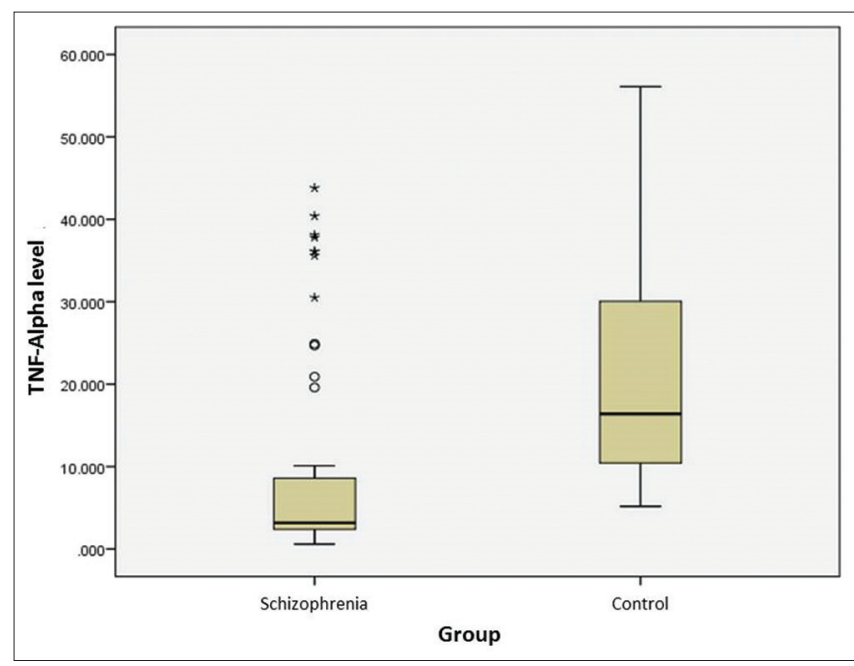

Figure 2: Boxplot graph result of the comparison analysis of tumor necrosis factor-alpha level between the schizophrenia group and the control group 


\section{Conclusions}

One of the factors that were thought to have an essential role in the development of schizophrenia was the inflammatory process that had begun since PwS was in the womb. The existing of cytokines affected the development of nerves, then after the PwS adult started interacting with the environment, the existence of genes in his body triggered the occurrence of schizophrenia. This study found that there was no correlation between TNFalpha and the severity of the symptoms of schizophrenia obtained based on the PANSS score, yet it had a positive correlation direction. Thus, it can be concluded that the higher levels of TNF-alpha would impact on the severity symptoms experienced by PwS. The difference of TNFalpha levels found in the PwS and control groups was that the lower TNF-alpha level in the schizophrenia group could be influenced by several things, including body mass index, race, smoking history, and other things that were not all controlled in this study. In the future, cohort studies and control of confounding factors will be more able to prove the correlation of cytokines with schizophrenia as one of the causes of the disease.

\section{References}

1. American Psychiatric Association. Diagnostic and Statistical Manual of Mental Disorders. $5^{\text {th }}$ ed. Philadelphia, PA: American Psychiatric Publishing; 2013.

2. Fan X, Goff DC, Hederson DC. Inflammation and schizophrenia. Expert Rev Neurother. 2007;7(7):789-96.

PMid: 17610386

3. Naudin J, Capo C, Giusan B, Mège JL, Azorin JM. A differential role for interleukin-6 and tumor necrosis factor-alpha in schizophrenia? Schizophr Res. 1997;26(2-3):227-33. https:// doi.org/10.1016/s0920-9964(97)00059-5

\section{PMid:9323355}

4. Erbagci AB, Herken H, Köyloüglu O, Yilmaz N, Tarakçioglu M. Serum IL-1beta, sIL-2R, IL-6, IL-8 and TNF-alpha in schizophrenic patients, relation with symptomatology and responsiveness to risperidone treatment. Mediators Inflamm. 2001;10(3):109-15. https://doi.org/10.1080/09629350123895

\section{PMid: 11545247}

5. Kowalski J, Blada P, Kucia K, Madej A, Herman ZS. Neuroleptics normalize increased release of interleukin- 1 beta and tumor necrosis factor-alpha from monocytes in schizophrenia. Schizophr Res. 2001;50(3):169-75. https://doi.org/10.1016/ s0920-9964(00)00156-0

PMid: 11439237

6. Theodoropoulou S, Spanakos G, Baxevanis CN, Economou M, Gritzapis AD, Papamichail MP, et al. Cytokine serum levels, autologous mixed lymphocyte reaction and surface marker analysis in never medicated and chronically medicated schizophrenic patients. Schizophr Res. 2001;47(1):13-25. https://doi.org/10.1016/s0920-9964(00)00007-4 PMid:11163541

7. O'Brien SM, Scully $P$, Dinan TG. Increased tumor necrosis factor-alpha concentrations with interleukin-4 concentrations in exacerbations of schizophrenia. Psychiatry Res. 2008;160(3):256-62. https://doi.org/10.1016/j. psychres.2007.11.014PMid:18722671

8. Tian L, Tan Y, Chen D, Lv M, Tan S, Soares JC, et al. Reduced serum TNF alpha level in chronic schizophrenia patients with or without tardive dyskinesia. Prog Neuropsychopharmacol Biol Psychiatry. 2014;54:269-4. https://doi.org/10.1016/j.pnpbp.2014.06.012 PMid:24995685

9. Lv MH, Tan Y.L, Yan SX, Tian L, Chen DC, Tan SP, etal. Decreased serum TNF-alpha levels in chronic schizophrenia patients on long-term antipsychotics: Correlation with psychopathology and cognition. Psychopharmacology. 2015;232(1):165-72. https:// doi.org/10.1007/s00213-014-3650-y PMid:24958229

10. Zhu F, Zhang L, Liu F, Wu R, Guo W, Ou J, et al. Altered serum tumor necrosis factor and interleukin- $1 \beta$ in first-episode drugnaive and chronic schizophrenia. Front Neurosci. 2018;12:296. https://doi.org/10.3389/fnins.2018.00296

PMid:29867314

11. Li R, Ma X, Wang G, Yang J, Wang C. Why sex differences in schizophrenia? Transl Neurosci (Beijing). 2016;1(1):37-42. PMid:29152382

12. Ochoa S, Usall J, Cobo J, Labad X, Kulkarni J. Gender differences in schizophrenia and first-episode psychosis: A comprehensive literature review. Schizophr Res Treatment. 2012;2012:916198. https://doi.org/10.1155/2012/916198 PMid:22966451

13. Ergün S, Yanartaş Ö, Kandemir G, Yaman M, Haklar G, Sayar K The relationship between psychopathology and cognitive functions with cytokines in clinically stable patients with schizophrenia. Psychiatry Clin Psychopharmacol. 2017;28(1):66-72. https://doi. org/10.1080/24750573.2017.1380920

14. Kubistova A, Horacek J, Novak T. Increased interleukin-6 and tumor necrosis factor alpha in first episode schizophrenia patients versus healthy controls. Psychiatr Danub. 2012;24 Suppl 1:S153-6. PMid:22945211

15. Ajami A, Abedian F, Hosseini SH, Akbarian E, AlizadehNavaei R, Taghipour M. Serum TNF- $\alpha$, IL-10 and IL-2 in schizophrenic patients before and after treatment with risperidone and clozapine. Iran J Immunol. 2014;11(3):200-9. PMid:25265997

16. Luo $\mathrm{Y}, \mathrm{He} \mathrm{H}$, Zhang $\mathrm{J}, \mathrm{Ou} \mathrm{Y}$, Fan $\mathrm{N}$. Changes in serum TNF- $\alpha$, IL-18, and IL-6 concentrations in patients with chronic schizophrenia at admission and at discharge. Compr Psychiatry. 2019;90:82-7. https://doi.org/10.1016/j.comppsych.2019.01.003 PMid:30782515

17. Turhan L, Batmaz S, Kocbiyik S, Soygur AH. The role of tumour necrosis factor alpha and soluble tumour necrosis factor alpha receptors in the symptomatology of schizophrenia. Nord $\mathrm{J}$ Psychiatry. 2016;70(5):342-50. https://doi.org/10.3109/080394 88.2015.1122079

PMid:26754110

18. Simamora RH, Loebis B, Husada MS. Comparison of serum levels of tumor necrosis factor alpha (TNF- $\alpha$ ) in batak male schizophrenic patients versus. Int J Life Sci Sci Res. 2018;4(2):1652-6. https://doi.org/10.21276/ijlssr.2018.4.2.6

19. Pollmächer T, Haack M, Schuld A, Reichenberg A, Yirmiya R. Low levels of circulating inflammatory cytokines-do they affect human brain functions? Brain Behav Immun. 2002;16(5):525-32. https://doi.org/10.1016/s0889-1591(02)00004-1 PMid: 12401466

20. Hoseth EZ, Ueland T, Dieset I, Birnbaum R, Shin JH, Kleinman $\mathrm{JE}$, et al. A study of TNF pathway activation in schizophrenia and bipolar disorder in plasma and brain tissue. Schizophr Bull. 
2017;43(4):881-90. https://doi.org/10.1093/schbul/sbw183 PMid:28049760

21. Mansur RB, Zugman A, Asevedo EM, da Cunha GR, Bressan RA, Brietzke E. Cytokines in schizophrenia: Possible role of anti-inflammatory medications in clinical and preclinical stages. Psychiatry Clin Neurosci. 2012;66(4):24760. https://doi.org/10.1111/j.1440-1819.2012.02354.x

PMid:22624729

22. Ferguson SA, Panos J, Varma V; 2019. Avalilable from: https:// www.fda.gov/media/97461/download. [Last accessed on 08 Aug 2020].

23. Brody GH, Yu T, Miller GE, Chen E. Discrimination, racial identity, and cytokine levels among african american adolescents. J Adolesc Health. 2015;56(5):496-501. https://doi.org/10.1016/j. jadohealth.2015.01.017 PMid:25907649

24. Brown MD, Fairheller DL, Thakkar S, Veerabhadrappa $P$ Park JY. Racial differences in tumor necrosis factor-alphainduced endothelial microparticles and interleukin-6 production. Vasc Health Risk Manag. 2011;7:541-50. https://doi.org/10.2147/ vhrm.s22930

PMid:21966220

25. Liu ZH, Ding YL, Xiu LC, Pan HY, Liang Y, Zhong SQ, et al. A meta-analysis of the association between TNF-alpha308G > a polymorphism and Type 2 diabetes mellitus in Han Chinese population. PLoS One. 2013;8(3):e59421. https://doi. org/10.1371/journal.pone.0059421

PMid:23527193

26. Nomura T, Honda T, Kabashima K. Multipolarity of cytokine axes in the pathogenesis of atopic dermatitis in terms of age, race, species, disease stage and biomarkers. Int Immunol. 2018;30(9):419-28. https://doi.org/10.1093/intimm/dxy015

PMid:29518197

27. Haralambieva IH, Ovsyannikova IG, Kennedy RB, Larrabee BR, Pankratz VS, Poland GA. Race and sex-based differences in cytokine immune responses to smallpox vaccine in healthy individuals. Hum Immunol. 2013;74(10):1263-6. https://doi. org/10.1016/j.humimm.2013.06.031

PMid:23806267 